\title{
Implementing a Framework for Qualitative Assessment of New Technical Solutions: A Case Study on CLT
}

\author{
Charlotte Svensson Tengberg $^{1}$ and Carl-Eric Hagentoft ${ }^{2}$ \\ ${ }^{1}$ Department of Architecture and Civil Engineering, Chalmers University of Technology, 41296 \\ Gothenburg Sweden and Skanska Sverige AB, Sweden, charlotte.tengberg@chalmers.se \\ ${ }^{2}$ Department of Architecture and Civil Engineering, Chalmers University of Technology, 41296 \\ Gothenburg, Sweden, carl-eric.hagentoft@chalmers.se
}

\begin{abstract}
New technical solutions are introduced at a fast pace in the Swedish construction industry, mainly driven by issues concerning costs and productivity. These new technical solutions can comprise new materials, new goods, new designs but also new processes. The record of accomplishment when introducing new technical solutions in the industry is not unproblematic and serial failures of different new technical solution have occurred. In an earlier interview study exploring introduction of new technical solutions in the Swedish construction industry, a common lack of thorough methods for evaluation of new solutions was identified. To address this issue, a case study was performed, exploring a method of evaluation with respect to building physics while implementing a cross laminated timber frame in a multifamily building. The case study uses a framework of assessment with focus on building physics. This paper presents the findings from the case study focusing on how evaluation of a new technical solution with respect to building physics is performed, together with an evaluation of the method, using the experiences of the participants in the case study.
\end{abstract}

Keywords: Serial Failure, Hygrothermal Performance, New Technical Solutions, Risk Assessment.

\section{Introduction}

Introducing new technical solutions in the construction industry is a challenge. Examples exist in the Swedish construction industry of both too slow adaptation of new technical solutions, i.e. loss of competitiveness or not reducing emissions of greenhouse gases, and too fast adaptation, i.e. poor quality and failure as the functional requirements are not sustained. Building physics failures, mainly moisture related, have been reported as a significant contributor to poor quality and related costs in the Swedish construction industry (Boverket, 2018). To systematically address the specific problems related to introduction of new technical solutions, the term Serial failures has been introduced defined as "Multiple cases of failure where a specific technical solution fails to sustain the functional requirement due to reasons in the design or production phases that could have been predicted by calculations or other assessment in the design stage." (Svensson Tengberg and Hagentoft, 2019)

In an interview study exploring introduction of new technical solutions in the Swedish construction industry, a common lack of (use of) thorough methods for evaluation of new solutions was identified (Svensson Tengberg and Hagentoft, 2019). It was also noted new technical solutions are usually introduced and evaluated at construction project level, with the supplier as a strong actor, providing the solution as well as related documentation.

Risk can be defined as the effect of uncertainty on objectives. Risk can be described by risk sources and potential events as well as consequences and likelihood (ISO 31000:2018, 2018). 
Risk management in the construction industry typically focuses on risks in the specific construction project. Although risk management in the construction industry complies with relevant standards (ISO 31000:2018, 2018) (ISO Guide 73:2009, 2009) (Project Management Institute, 2017), there is a lack of guidelines and systematic approach for selecting appropriate risk identification techniques according to (Siraj and Robinson Fayek, 2019). In a construction project there is a wide array of risks handled, e.g. risks related to management, commercial or technical issues. Specifically to address risks related to building physics/moisture performance, there is an Industry Standard, ByggaF (Mjörnell, Arfvidsson and Sikander, 2012), suggesting a common risk identification in the design stage where all actors in the design group should conduct a moisture risk analysis based on a checklist for each building part as a starting point. The checklist starts from applying relevant moisture sources to the designs and assess the (unwanted) effects on the design. A more elaborate framework for testing, evaluating and documenting variations in performance of building envelopes was suggested in a research project focusing on reliability through probability assessment of performance and cost (Bednar and Hagentoft, 2015) and (Sasic Kalagasidis and Rode, 2015), see Figure 1.
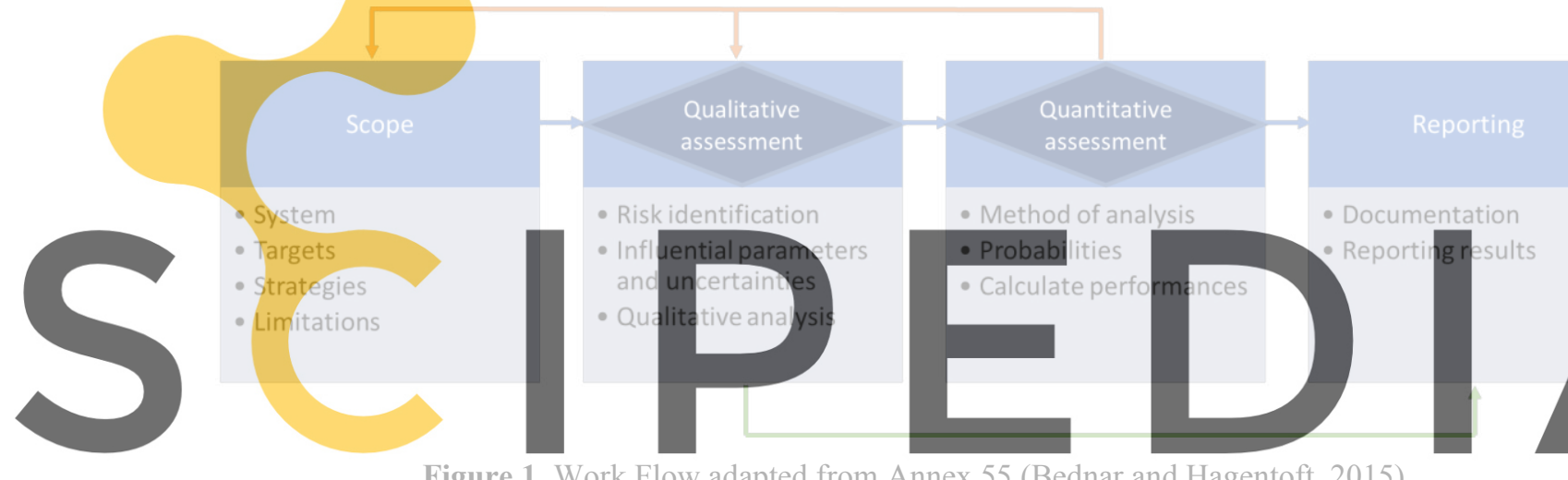

Figure 1. Work Flow adapted from Annex 55 (Bednar and Hagentoft, 2015).

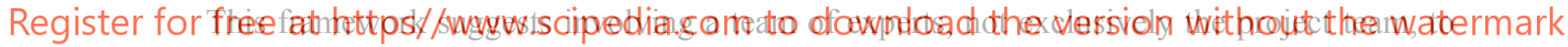
perform the risk assessment and to perform the assessment methodically and transparently i.e. well documented. In (Pallin, 2013) it is suggested to perform the risk identification using common tools, e.g. ETA, FTA or VMEA. However, although there are suggestions of the format of the workshop and possible risk identification tool this is not further defined.

The objective of this paper is twofold, firstly to investigate the potential of the framework for qualitative assessment in a case study and secondly to collect data on risks associated to the case study. This paper is a part of a research project initiated with the aim of reducing risk of serial failure related to building physics when introducing new technical solutions in the construction industry.

\section{A Case Study}

To investigate the potential of the framework for qualitative assessment, a case study was designed. The case chosen for investigating the framework was Fulfilment of functional requirements related to building physics using a technical solution of cross-laminated timber in a multi-dwelling building. Cross-laminated timber was chosen as it is a relatively new technical solution, based on a material, wood, that historically has been associated with moisture issues. (Svenskt Trä, 2017) (Olsson, 2019). The outline of the work was performed 
according to the first two parts of the framework in Figure 1: The scope and the Qualitative risk assessment including an expert workshop. :

- Defining the scope. The scope is described by The system, The targets, The strategies as well as The limitations. As the case study is not a retrofit, the existing conditions are not relevant and therefore omitted. This material was prepared before the workshop.

- Qualitative assessment, Risk identification. Preparing the expert workshop. To prepare for the expert workshop, a three-hour pre-workshop was performed with six participants representing the competences project management, designing engineer, moisture expert, and building physics. The objective of the pre-workshop was to try out the format and classifications before preparing material to the final workshop. The agenda was divided into Introduction, Theory and objectives, followed by Risk identification firstly on a general level and then in more detail, while discussing likelihood and consequences. As a result, a preparation material for the expert workshop was compiled and distributed.

- Qualitative assessment, Risk identification. Expert workshop. An expert workshop constituted the core of the qualitative risk assessment, as suggested in the framework. A four-hour expert workshop was designed, with the scope to identify and assess risks related to building physics for the technical solution. More specific, the focus was on "Not to exceed the critical moisture condition in the CLT structure" during production or operation of the building. The workshop started with a presentation of the participants, introduction to the background including an overview on risk management and objectives of the

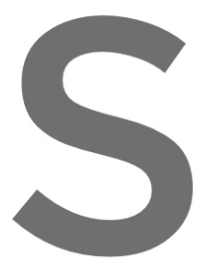
workshop. The risk assessinent was divided into two sub w
sources and potential events) and risk analysis (focus on
two parts were summarised at the end of thd day. The particip
key actors with different perspectives of the building proc
two authors took the part of workshop leaders.
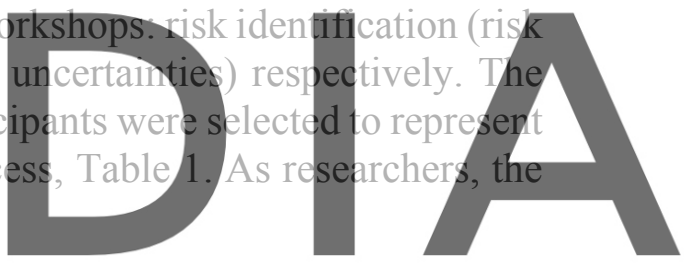
Table 1. Workshop participants.

\begin{tabular}{|c|c|c|c|}
\hline Profession & Gender & Profession & Gender \\
\hline Project manager & $\mathrm{M}$ & Supplier, CLT & $\mathrm{M}$ \\
\hline Design manager & $\mathrm{F}$ & Supplier, CLT & $\mathrm{M}$ \\
\hline Construction manager & $\mathrm{M}$ & Supplier, CLT & $\mathrm{M}$ \\
\hline Architect & $\mathrm{F}$ & Estimator & $\mathrm{M}$ \\
\hline Designing engineer & $\mathrm{M}$ & Academia & $\mathrm{M}$ \\
\hline Designing engineer & $\mathrm{M}$ & Academia & $\mathrm{F}$ \\
\hline Building physics & $\mathrm{M}$ & & \\
\hline
\end{tabular}

- Evaluating the framework. After the workshop, notes from the workshop were sent out to the participants together with a questionnaire with a few questions concerning their experience of the workshop, including the preparations, the different sections of the workshop and new insights.

\section{Results and Discussion}

\subsection{Defining the Scope}

One of the results was the scope definition according to the framework. It was summarised before the workshop and presented to the participants.

System. The system is defined as a five-storey multi-dwelling building with 18 apartments in a point block, using a cross-laminated timber structure situated in the metropolitan area of

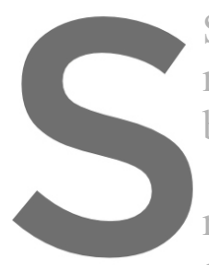
Stockholm. The buildin multi-dwelling building buildings and four to six s Targets. The target requirements described addressing both construction phase and operation of the building. Other $\mathrm{f}$

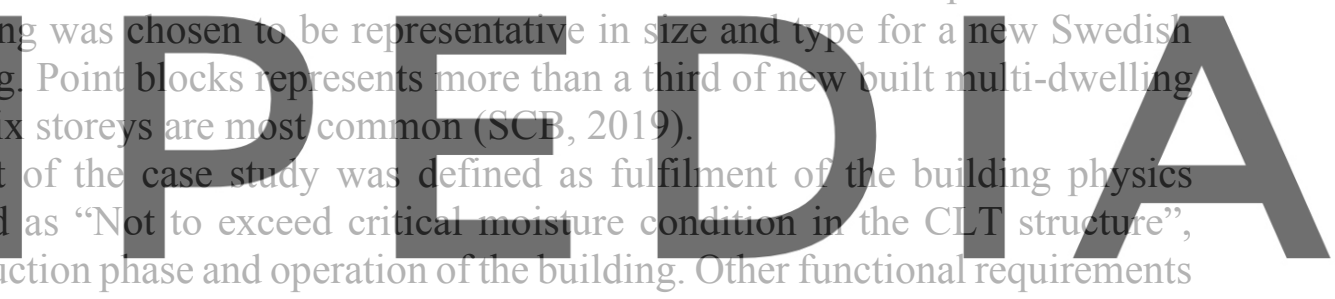

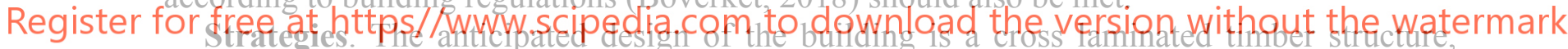

including a timber structure in exterior walls and intermediate floors as well as balconies. The roof is assumed to be a timber frame construction. Energy performance of the building is assumed to be according to Swedish Building Regulations with U-values for walls, roof and windows in the range of $0.14 / 0.13 / 0.8 \mathrm{~W} / \mathrm{m}^{2} / \mathrm{K}$ respectively (average $\mathrm{U}$-value of $0.34 \mathrm{~W} / \mathrm{m}^{2} / \mathrm{K}$ ). A wooden façade is chosen. The building is heated to $22^{\circ} \mathrm{C}$. The building is heated by district heating and an exhaust air heat pump. Air tightness of the building is expected to be $0.31 / \mathrm{s} / \mathrm{m}^{2}$ at $50 \mathrm{~Pa}$.

Limitations. The assessment is made on basis of the prerequisites above. If changes are made, an update of the assessment should be performed.

\subsection{Risk Identification During Expert Workshop}

One of the results from the workshop was the thorough risk identification concerning building physics. At the workshop, the main risk categories as compiled from the hand-ins were presented and the participants were asked to supplement and adjust the risk list. In a summary of the risk identification, the participants were asked to vote on top-5 risks of interest. The issue that was given far most relevance was moisture during the construction phase, specifically 
Precipitation during construction. Other risks of high relevance were noted: Hygrothermal performance of external wall (including façade), Window connections, Balconies and Walls with membranes on both sides. It can also be noted, Water leakage from pipes was lifted as the effects were considered highly unknown. The results from the risk identification and the voting are shown in Table 2.

Table 2. Risk identification "To exceed critical moisture conditions in the CLT structure". Phase and location in the building are used as categories. Constr $=$ Construction phase, $\mathrm{Op}=$ Operation phase.

\begin{tabular}{|c|c|c|}
\hline Phase/location & General description & Votes \\
\hline Constr/General & Precipitation during construction & 18 \\
\hline Constr/General & Material moist/damaged by other materials/construction at site & 4 \\
\hline Constr/General & Material moist/damaged before construction & 1 \\
\hline Constr/General & Inferior air and moisture tightness between elements & 8 \\
\hline Op/Wall & Hygrothermal performance of external wall design (incl. facade) & 6 \\
\hline Op/Roof & Hygrothermal performance of external roof design & n.a.* \\
\hline Op/Details & Bushings in wall & 1 \\
\hline Op/Details & Connection wall/base & 1 \\
\hline Op/Details & Connection wall/window & 4 \\
\hline Op/Details & Balconies and connection wall/balcony & 5 \\
\hline Op/Details & Connection wall/roof & 0 \\
\hline Op/Details & Bushings in roof & n.a.* \\
\hline Op/Details & Fastenings in rogf & n.a.* \\
\hline $\mathrm{Op} /$ Wet room & Walls with membri & 3 \\
\hline Op/Wet room & Bushings in wet ro & 0 \\
\hline Op/Wet room & Fastenings in wet rom walls & \\
\hline Op/Wet room & Indoor climate exceeds critical conditions & \\
\hline $\mathrm{Op} / \mathrm{HVAC}$ & Condensation at pipes & \\
\hline Op/HVAC & Leakage through deformations & 0 \\
\hline
\end{tabular}

\subsection{Risk Assessment Düring Expert Workshop: Precipitation During Production}

Another result from the workshop was the risk assessment of a selected risk: Precipitation during the production phase. This risk was chosen as the participants identified it by far the most relevant risk. For the assessment, the participants were asked to identify relevant influential parameters and related available data/documentation as well as different types of uncertainties. The identified influencing parameters referred to Design and material, Loads, Production methods or to Organisational issues and were compiled in a table together with relevant influential parameters, uncertainties and correlations. An illustrated summary of the table with influencing parameters and a suggestion of which type of uncertainty associated with them is shown in Figure 2. Similar tables and illustrations were also developed for the other top-3 risks: Hygrothermal performance of exterior wall and Balconies. However, these are not presented in this paper. 


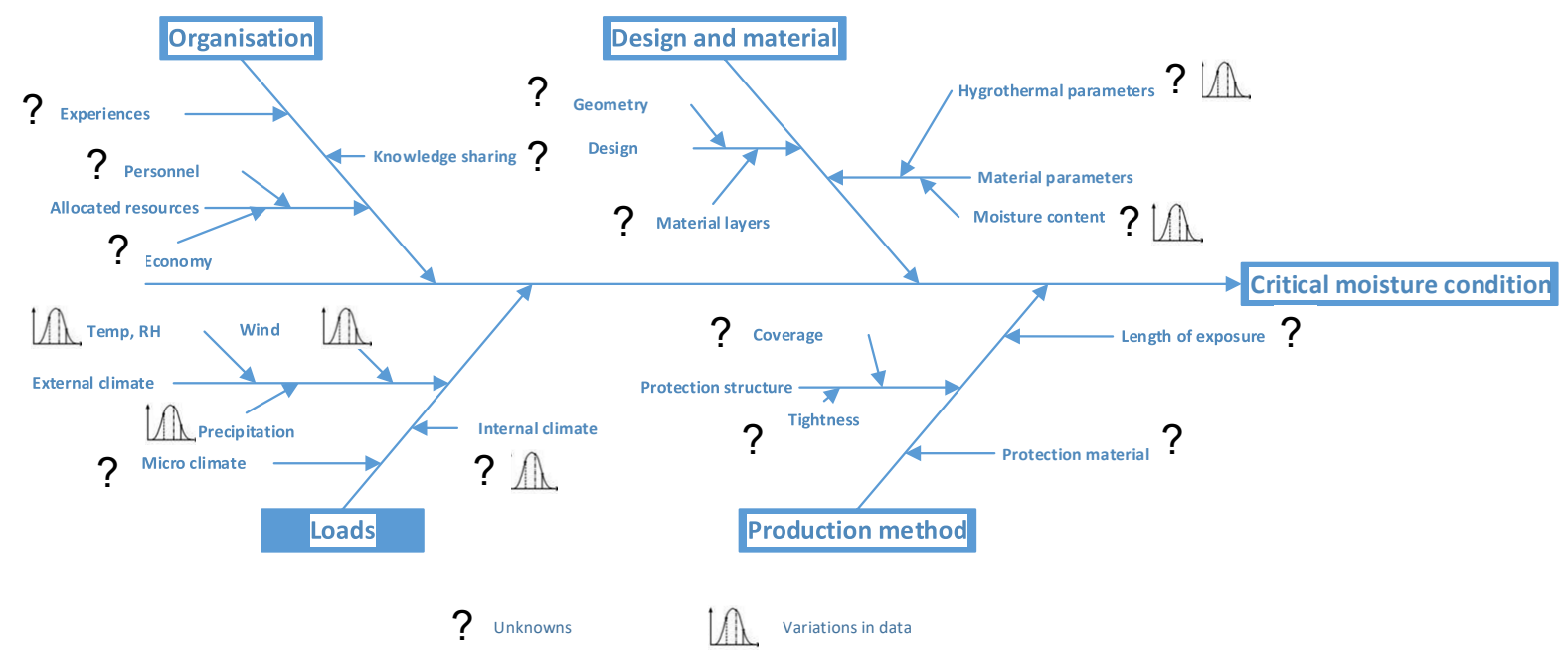

Figure 2. Precipitation during the production phase: Ishikawa graph showing identified influencing parameters for the risk of exceeding the critical moisture conditions. Also, anticipated type of uncertainties, unknowns and variations in data, are noted.

\subsection{Risk Assessment During Expert Workshop: Important Uncertainties/Unknowns}

The third result of the workshop is the identification of important uncertainties/unknowns for the case. After the top-3 risks with relevant influential parameters, uncertainties and correlations had been presented, the uncertainties nerceived to have the most importance were identified by the participants:

- Unknown hygrothermal behaviour performance of material

- Unknown moisture exposure and loads

Unknown effects of water leakage during construction phase (lack of data/variations)

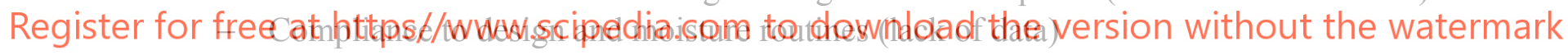

- Knowledge in the organisation (lack of data)

- Responsibility of different actors (lack of data)

\subsection{Workshop Experiences}

In the pre-workshop, valuable reflections were made. The suggested agenda was slightly changed, as the introduction was extended to create common understanding. The grouping of risks was added as an activity and thus, the continued risk description was left with less time for estimation of likelihood and consequences of identified risks. Also, the participants perceived the ranking of likeliness and consequences as difficult. Another experience was that several issues were lifted by the participants, where the level of uncertainty was low, but solutions had impact on other objectives (primarily costs but also other functional requirements). The insights from the pre-workshop resulted in a more thorough preparation material including a hand-in of three to five risks. The material was distributed to the participants two weeks in advance. The objective of the preparation material was to reduce time spent on these issues at the workshop. 
At the main workshop the participant expressed their expectations. More than half of the expectations were oriented towards possibilities and finding solutions in general or to find a solution for a specific issue, i.e. the issue of moisture during the construction phase: "Is there need for weather protection?". Other expectations on the workshop were to know more about the uncertainties of the technical solution in general or to be able to quantify the costs related to risks. One of the participants expressed a wish to be able to "...follow the risks from design to production." At the end of the workshop, the participants agreed on that many of the expectations were met and that the workshop had provided a greater understanding and awareness of risks in general, and of the three selected risks specifically.

Eight out of eleven answered the survey after the workshop. The answers indicate a strongly positive experience of the workshop. The participants valued the overall experience of the workshop as good or very good ( 3 and 5 respectively), and most participants indicated that the workshop gave a lot of new insights in the subject. There were different opinions on the length of different parts of the workshop, with a slight tendency to experiencing the risk assessment and the summary as too short. The preparation material was perceived as helpful or very helpful, but a few of the participants had not had the time to use it.

\section{Conclusions}

The general perception of the workshop format was positive, and the expert workshop was perceived to give a lot of new insights to the participants.

Setting up appropriate boundary conditions of the works initiated workshop was broad, aiming at identifying relevant iss
using a cross-laminated timber structure. A broad topic will gir while a targeted topic analysed part of the naterial at the workshop, Preferably, the workshop is repeated on increas

A well-prepared workshop with preparation material and hand-ins will help the process,

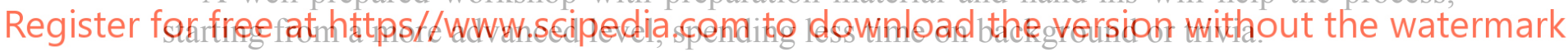

Likeliness and consequences of different events are perceived difficult when introducing new technical solutions. This was handled at the workshop with focusing on establishing a thorough list of relevant uncertainties.

The different competences at the workshop were perceived as a prerequisite to enable a fruitful risk identification.

\subsection{Future Work}

Future work will take two main paths:

- Continued analysis of the case study. Analysis of the data collected will result in a thorough qualitative assessment and in a quantitative assessment in line with the qualitative assessment, with the aim to address and reduce risks in multi-dwelling buildings with CLT.

- Continue to the adaption of the framework to the scope of introducing new technical solutions in the Swedish construction industry, by continuing the case study of multidwelling buildings with CLT and possibly extend with other case studies. 


\section{Acknowledgements}

Support from the Development Fund of the Swedish Construction Industry (SBUF) is gratefully acknowledged.

\section{ORCID}

Charlotte Svensson Tengberg: https://orcid.org/0000-0002-8648-0871

Carl-Eric Hagentoft: https://orcid.org/0000-0002-1616-361

\section{References}

Bednar, T. and Hagentoft, C.-E. (2015). Risk management by probabilistic assessment. Development of guidelines for practice, IEA Annex 55, RAP-RETRO. Göteborg, Sweden: Department of Civil and Enivronmental Engineering, Chalmers University of Technology.

Boverket. (2018). Boverkets byggregler - föreskrifter och allmänna råd, BBR. BFS 2011:6 med ändringar till och med BFS 2018:4 (Boverket's Building regulations). Karlskrona, Sweden: Boverket.

Boverket. (2018). Kartläggning av fel, brister och skador inom byggsektorn. Rapport 2018:36 (Survey on faults, defects and damage in the building sector). ISBN: 978-91-7563-612-2: The Swedish National Board of Housing, Building and Planning, Karlskrona, Sweden.

Fuktcentrum. (2013). Industrial standard - ByggaF. Retrieved from http://www.fuktcentrum.lth.se/verktyg-ochhjaelpmedel/fuktsaekert-byggande/byggaf-metoden/

ISO 31000:2018. (2018). Risk management - Guidelines. ISO 31000:2018, IDT. Geneva, Switzerland: International Organization for Standardization.

ISO Guide 73:2009. (2009). Risk management - Vocabulary. Guide 73. Geneva, Switzerland: International Organization for Standardization.

Mjörnell, K., Arfvidsson, J. and Sikander, E. (2012). A Method for Including Moisture Safety in the Building Process. Indoor Built Environment 21, p583-594.

Olsson, L. (2019). Fuktsäkerhet vid without weather protedio

Pallin, S. (2013). Risk Assessi and Environmental Eng

roject Management Institute. Institute, Inc.
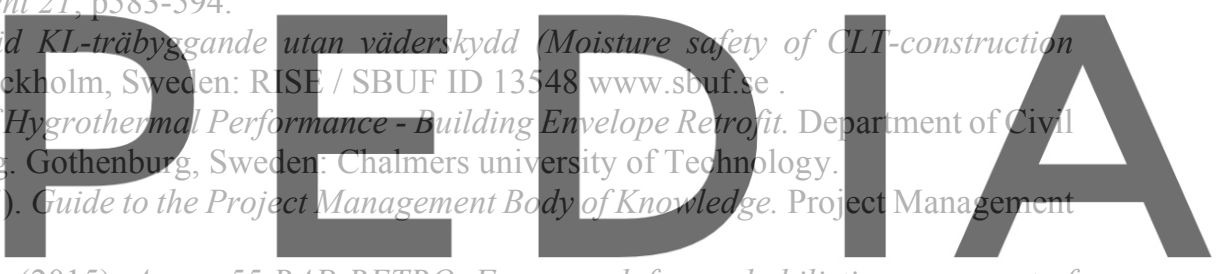

Sasic Kalagasidis, A. and Rode, C. (2015). Annex 55 RAP-RETRO. Framework for probabilistic assessment of

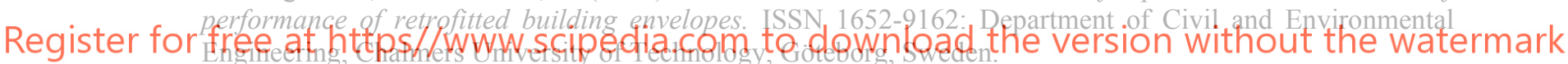

SCB. (2019, 10 10). Statistical database. Retrieved from Dwellings in newly constructed conventional multidwelling buildings by number of storeys in the building 2007-2017: http://www.statistikdatabasen.scb.se/pxweb/en/ssd/

Siraj, N. B. and Robinson Fayek, A. (2019). Risk Identification and Common Risks in Construction: Literature Review and Content Analysis. Journal of Construction Engineering and Management, 145/9 DOI: 10.1061/(ASCE)CO.1943-7862.0001685.

Svenskt Trä. (2017). KL-trähandboken. Fakta och projektering av KL-träkonstruktioner (CLT hand book). Stockholm, Sweden: Svenskt Trä.

Svensson Tengberg, C. and Hagentoft, C.-E. (2019). Introducing New Technical Solutions in the Swedish Construction Industry - Interviews with Key Actors. ASHRAE Thermal Performance of the Exterior Envelopes of Whole Buildings XIV International Conference, (pp. 810-817). Clearwater, Florida, USA. 